\title{
Effectiveness of two Live Well Suffolk weight management interventions in reducing weight in overweight and obese adults
}

\author{
D. J. Pipe ${ }^{1}$, H. Osborn ${ }^{2}$ and F. Ibrahim ${ }^{1}$ \\ ${ }^{1}$ University Campus, Waterfront Building, Neptune Quay, Ipswich, Suffolk. IP4 1QJ and ${ }^{2}$ Live Well Suffolk, Adelphi \\ House, 8 Turret Lane, Ipswich, Suffolk IP4 IDL
}

Overweight and obesity due to poor diet and physical inactivity contribute significantly to the burden of cardiovascular disease, diabetes, cognitive impairment and premature mortality ${ }^{(1)}$ with associated health and social care costs. Obesity prevalence varies by age, gender and socio-economic status ${ }^{(2)}$ and adults tend to gain weight with age, particularly if they are physically inactive ${ }^{(3)}$. Local authorities have commissioned lifestyle weight management interventions for priority groups and the evaluation of intervention outcomes is necessary to monitor cost-effectiveness ${ }^{(4)}$. Anonymised data was used from Live Well Suffolk records and ethical approval was not required. Eligibility for both interventions was restricted to black and minority ethnic groups, full time carers, those with a mental health condition or from deprived postcode areas and the weight management (WM) programme was limited to those with BMI $>28 \mathrm{~kg} / \mathrm{m}^{2}$ plus a medical condition or BMI $>30 \mathrm{~kg} / \mathrm{m}^{2}$. The aim of this study was to compare the effectiveness of two interventions which were implemented at Live Well Suffolk: 1) Weight management (WM), 2) Physical activity and healthy eating (PA \& HE).

\begin{tabular}{|c|c|c|c|c|c|}
\hline Characteristic & WM $(n=100)$ & SD & PA \& HE $(n=140)$ & SD & $\mathrm{P}$ value \\
\hline Age - years mean & $52 \cdot 84$ & $14 \cdot 38$ & $50 \cdot 86$ & $15 \cdot 14$ & *0.306 \\
\hline BMI - kg/m2 mean & 37.73 & 6.99 & $27 \cdot 52$ & 5.99 & $* *<0.001$ \\
\hline Ethnicity - no & \multirow{2}{*}{\multicolumn{2}{|c|}{$88: 3: 9$}} & & & \\
\hline White : black : other & & & \multicolumn{2}{|c|}{$119: 6: 15$} & $* 0.783$ \\
\hline Gender - no & \multirow{2}{*}{\multicolumn{2}{|c|}{$76: 24$}} & \multirow{2}{*}{\multicolumn{2}{|c|}{$118: 22$}} & \\
\hline Female : male & & & & & $* 0.075$ \\
\hline
\end{tabular}

$* \mathrm{p}>0.05$ indicating no significant difference between the 2 groups. ${ }^{* *}$ BMI was significantly greater in the WM group.

The mean weight change was $-2 \cdot 24 \mathrm{~kg}(-2 \cdot 19 \%)$ in the WM group which was significantly greater $(\mathrm{p}<0.05)$ than $-0 \cdot 9 \mathrm{~kg}(-1 \cdot 17 \%)$ in the PA and HE group.

\begin{tabular}{|c|c|c|c|c|c|c|c|c|c|c|}
\hline \multirow{3}{*}{ Age group (yrs) } & \multicolumn{5}{|c|}{ Weight management } & \multicolumn{5}{|c|}{ PA and healthy eating } \\
\hline & \multicolumn{3}{|c|}{ Weight change } & \multicolumn{2}{|c|}{$\%$ weight change } & \multicolumn{3}{|c|}{ Weight change } & \multicolumn{2}{|c|}{$\%$ weight change } \\
\hline & $\mathrm{n}$ & Mean & $\mathrm{SD}$ & Mean & SD & $\mathrm{n}$ & Mean & SD & Mean & $\mathrm{SD}$ \\
\hline $18-39$ & 20 & $-0.69 *$ & $2 \cdot 41$ & -0.44 & $2 \cdot 21$ & 33 & $-1 \cdot 15$ & $2 \cdot 22$ & -1.42 & $2 \cdot 86$ \\
\hline $40-59$ & 39 & $-2 \cdot 85$ & $3 \cdot 61$ & -2.65 & $3 \cdot 24$ & 58 & $-1 \cdot 12$ & $2 \cdot 31$ & -1.51 & $3 \cdot 28$ \\
\hline $60+$ & 41 & $-2 \cdot 42$ & $2 \cdot 52$ & $-2 \cdot 61$ & $2 \cdot 77$ & 49 & -0.48 & 1.68 & $-0 \cdot 61$ & $2 \cdot 49$ \\
\hline
\end{tabular}

Derived by unmatched ANOVA for between age group comparison, followed by LSD post hoc test; *weight change in the WM intervention in the youngest age group was significantly lower $(\mathrm{p}<0.05)$ than in the older age groups but not in the PA \& HE intervention where there was no significant difference.

No significant difference was found in either mean weight change or mean $\%$ weight change by gender within each intervention. In conclusion, mean absolute and \% weight loss were significantly greater in the WM intervention and overall, 50/193 overweight and obese participants achieved at least $3 \%$ weight reduction.

1. Murray C J L, Richards M A, Newton J N et al. (2013) The Lancet 381, 997-1020.

2. Moody A (2013) Health Survey for England 2012

3. Golubic R, Ekelund U, Luben R et al. (2013) International Journal of Obesity 37, 404-409.

4. Logue J, Allardice G, Gillies M et al. (2014) BMJ Open. 